\title{
MEN AND SOCIAL TRAUMA OF COVID-19 PANDEMIC. THE MALADAPTIVENESS OF TOXIC MASCULINITY
}

\author{
MONIKA FRĄCKOWIAK-SOCHAŃSKA ${ }^{1}$ \\ ${ }^{1}$ Adam Mickiewicz University in Poznań, Szamarzewskiego 89 C, 60-568 Poznań, Poland. ORCID: \\ 0000-0002-8318-5295, Email: monikafs@amu.edu.pl
}

ABSTRACT: The first purpose of this paper is to analyze the direct and indirect, shortand long-term consequences of the COVID-19 pandemic for men. The second purpose is to identify the mechanisms underlying the present and predicted pandemic's impact on men's life and health (both somatic and mental). The author interprets the higher men's mortality rates due to coronavirus and the males' suicide rates that heightened from the beginning of the pandemic due to life-style that reflects the toxic masculinity norms. This paper's theoretical framework is determined by the social (cultural) trauma theory and the Critical Studies on Men and Masculinities. The method used for the present study is desk research based on the integrated literature review including the results of empirical research directly or indirectly addressing males' experience of the COVID-19 pandemic from the years 2019 and 2020, the previous pandemics (SARS in 2002-2004 and Ebola in 2014), other social crises caused by economic and political processes, and research explaining men's stress-related behaviors.

KEYWORDS: toxic masculinity, social trauma, COVID-19 pandemic, men's mortality, men's suicide, male depression

\section{INTRODUCTION}

The first purpose of this paper is to analyze the direct and indirect, short- and longterm consequences of the COVID-19 pandemic ${ }^{1}$ for men. The second purpose is to

\footnotetext{
${ }^{1}$ The COVID-19 pandemic is an ongoing pandemic of coronavirus disease caused by severe acute res-
} piratory syndrome coronavirus 2 (SARSCoV2). The disease was first identified in December 2019 in Wu- 
identify the mechanisms underlying particular present and predicted consequences of the pandemic for men's life and health (both somatic and mental).

Based on the hitherto WHO's data, men are dying from coronavirus more often than women worldwide (Global Health 50/50 2020; Griffith, Sharma, Holliday, et al. 2020). The proportion of males' deaths of COVID-19 ranges from about $57 \%$ to $75 \%$, depending on the country (Bischof, Wolfe, \& Klein 2020; Sharma, Volgman \& Michos 2020; Xie, Tong, \& Guan 2020). ${ }^{2}$ Moreover, male patients develop more severe symptoms of COVID-19 (Alkhouli, Nanjundappa, Annie et al. 2020; Griffith, Sharma, Holliday et al. 2020). The causes of men's higher mortality and more acute course of the disease are not fully understood. The biological factors do not entirely explain these differences ${ }^{3}$, because the individuals' health condition primarily results from the life-style and socio-cultural norms of behaviors. Moreover, men are particularly vulnerable to the most severe consequences of the mental health crisis arising as a repercussion of pandemic and related social crisis, namely suicide. Taking a gender perspective while dealing with somatic and mental health issues enables us to understand the mechanisms that may seem invisible and elusive when abstracting from gender. In this context, some medical issues and social problems related to them can be interpreted as "the side effects" or Merton's (1968) latent functions of socialization to specific gender roles.

The theoretical framework of this paper is determined by the social (cultural) trauma theory (Alexander 2004, Sztompka 2002) and the Critical Studies on Men and Masculinities (Pini, Pease 2013).

The COVID-19 pandemic meets the criteria of social trauma since it leads to rapid, unexpected, radical changes in diverse areas of social life. It affects politics, the economy and labor market, education, and individuals' everyday life. These changes manifest themselves in altering the systemic regulations, the principles of everyday routine, and the priorities declared at the social and the personal level. The world of habits, customs, and meanings, stable so far, gets disturbed. People confront the new

han, China. The World Health Organization declared the outbreak a Public Health Emergency of International Concern on 30 January 2020 and a pandemic on 11 March. As of 11 September 2020, more than 28.1 million cases have been reported in more than 188 countries and territories, resulting in more than 909,000 deaths; more than 19 million people have recovered (https://en.wikipedia.org/wiki/COVID-19_pandemic, access: 11 September 2020).

${ }^{2}$ More exact data will be presented and discussed in the further fragments of the paper.

${ }^{3}$ The researchers consider factors resulting from better immunity among women due to the additional $\mathrm{X}$ chromosome to explain the discrepancy from the biological perspective. "This differential regulation of immune responses in men and women is contributed by sex chromosome genes and sex hormones, including estrogen, progesterone, and androgens. Sex-specific disease outcomes after viral infections are attributed to sex-dependent production of steroid hormones, different copy numbers of immune response X-linked genes, and the presence of disease susceptibility genes" (Griffith, Sharma, Holliday 2020:2, Sharma, Volgman, Michos 2020). The research on the cellular response mechanism to the SARS$\mathrm{CoV}-2$ virus revealed that cardiac diseases in men strengthen the sex effect. Men have higher plasma ACE2 levels than women do. A recent study of patients with heart failure showed that plasma ACE2 concentrations were higher than average in men and higher in men than in women, possibly reflecting higher tissue expression of the ACE2 receptor for SARS-CoV infections (Sama, Ravera, Santema et al. 2020; Griffith, Sharma, Holliday et al. 2020). In the case of the acquired heart disease, biological factors play a part, and the psycho-social ones. 
forms of risk and lose safety since everyday activities such as interacting with other people in regular social situations became hazardous. The economic consequences of pandemic lead to unemployment, worsening living conditions, and insecurity for many people. Simultaneously, the pandemic reveals the problems of inequalities in distributing resources that enable individuals to protect themselves. Social trauma spotlights pre-existing problems such as scarcity of resources in health care and other institutions that have crucial meaning in critical situations. (Frąckowiak-Sochańska, 2020). Finally, social trauma leads to the revision of how the fundamental values, norms, and notions that constitute the culture are conceptualized (Sztompka 2002:463). This assumption also addresses socially constructed concepts of gender. In the context of social trauma, some patterns of masculinities may seem notably dysfunctional. The present analysis focuses on the maladaptive patterns of masculinity that become visible in the situation of the COVID-19 pandemic. In other words, social trauma burdens the individuals with stress, the reactions to which may reveal the dysfunctional patterns described in the categories of "toxic masculinity."

For the present analysis, "toxic masculinity" is defined as a concept that serves as an analytical instrument to identify traditional attitudes and practices among men that are based on the culturally constructed image of specifically understood strength, dominance, emotional restrain regardless of they lead to exercising power in particular men's lives (Connel, Messerschmmidt 2005, Kimmel 1994, Jewkes, Morrell, Hearn 2015). Although new masculine patterns and the theoretical reflection on them emerge (Anderson 2009, Elliott 2016, Bridges, Pascoe 2014), traditional (and often dysfunctional) masculinity patterns are still an essential point of reference in contemporary men's and boys' socialization process. Therefore many men face the consequences of these patterns in their lives. In January 2019, the American Psychological Association (APA) released guidelines on working with men and boys and precisely dealing with those who adhere to traditional masculinity patterns (de Boise 2019). The APA described traditional masculinity as „marked by stoicism, competitiveness, dominance, and aggression which is, on the whole, harmful" (Pappas 2019, de Boise 2019). The arguments for APA's guidelines focus on data according to which men commit $90 \%$ of homicides in the United States and represent $77 \%$ of homicide victims. They are the demographic group most at risk of being victimized by violent crime. They are 3.5 times more likely than women to die by suicide, and their life expectancy is 4.9 years shorter than women's (Pappas 2019). In this context, the notion of toxic masculinity addresses the conformity to gendered attitudes that manifest more frequently in men's behavior that are actively damaging for others and the men themselves. The anti-social components of toxic masculinity include violence, transphobic, misogynistic, homophobic or racist bullying, sexual assault, or harassment. The auto-destructive factors comprise excessive drinking and its consequences, physical injuries from fighting, steroids, body dysmorphia, drug-taking, inability to express emotions (de Boise 2019). In the pandemic's situation, toxic masculinity implies non-compliance to safety norms that expose an individual and people around him to the risk of contagion. In the face of an epidemic emergency, not wearing a mask or resisting other security regulations can be interpreted as both anti-social (Solnit 2020, Harsin 
2020) and self-destructive attitude.

The present paper's central thesis boils down to the assumption that toxic masculinity patterns manifest themselves in anti-health and risky behaviors that result in higher males' mortality on COVID-19, more severe course of the disease, and the increase of males' suicide risk in the face of pandemic's socioeconomic consequences.

\section{THE RESEARCH METHODOLOGY}

The method used for the present study is desk research, based on the integrated literature review procedure. This strategy allows the inclusion of research employing multiple methodologies to capture the context, processes, explicit and implicit mechanisms addressing a research problem (Muennich Cowell 2012; Whittemore \& Knafl 2005). Two main research problems boil down to the following questions. What are the direct and indirect, short- and long-term consequences of the COVID-19 pandemic for men? What mechanisms underlay particular present and predicted consequences for men's life and health? In order to answer the above questions, a consecutive research strategy was performed.

The author used Google Scholar to identify scientific papers and research reports published until 1 September 2020. The analysis consisted of two stages. The first stage focused on the direct consequences of the COVID-19 pandemic for men's somatic health and life hazard. The search keywords were: "COVID-19", "coronavirus," "pandemic," "men," "women”, "gender." The studies were selected and reviewed for potential inclusion. The studies were included if they analyzed gender differences in COVID-19 and addressed the biological factors and the sociocultural ones. The second stage focused on the pandemic's indirect consequences for men's mental condition and suicide risk. The search keywords were: "COVID-19”, "coronavirus”, "pandemic”, "social crisis", "men”, "women”, “suicide”. The studies were included if they analyzed from a gender perspective the relations between social crisis caused by a pandemic and suicide rates.

At both stages, the supplementary searches were performed as the key themes emerged from the analyzed material. At the first stage, these were: "alcohol abuse and nicotine consumption by men and women," "male and female reactions to stress," "gender differences in risk behaviors," "gender differences in help-seeking behaviors." At the second stage, the additional searched themes addressed "male depression" since suicidal behaviors and depression are inextricably linked.

Throughout the whole research process, the inclusion criteria were: validity, reliability, and the explanatory value of the studies. The selected papers addressed the research carried out in 2019 and 2020 at the main stages and after 2000 at the supplementary searches. The selected materials included complete descriptions of methodology procedures. The research contributed to understanding the mechanisms underlying the specificity of males' morbidity and mortality of COVID-19 and higher men's suicide risk resulting from the pandemic's social crisis.

The author is aware that it is difficult to compare and generalize studies on the same topic because of the large number of variables in studies of this type. The myriad 
of studies that have been published in the literature has utilized diverse study populations that may have different perspectives regarding gender differences in health. In the face of the above challenge, the author focused foremost on international analyses that employed the meta-analysis procedures. These studies' results indicate some common, trans-local, and cross-cultural patterns that may be interpreted in the context of Critical Studies on Men and Masculinities.

Searching for some general mechanisms related to the influence of the toxic masculinity patterns on males' health in diverse populations was performed deliberately, with the awareness of the potential differences underestimation risk. However, this procedure is justified according to the previous studies picturing toxic masculinity as an intercultural phenomenon (de Boise 2019; Harsin 2020). Since the present research is preliminary, it focuses on the general mechanisms, the local variants of which should be submitted to forward, more detailed investigations.

\section{TOXIC MASCULINITY AND MORTALITY DUE TO COVID-19 - RISK FACTORS AND RESPONSE PATTERNS IN THE FACE OF HAZARD}

Disease outbreaks affect women and men differently and increase gender inequalities that have already existed in different societies (UNFPA 2020). Moreover, they intensify the social problems within gender categories and sharpen the differences between males' and females' subcategories depending on their economic resources and social and cultural capital. As Christina Ewig (2020) points, gender and its interactions with class, race, and other variables that determine the individuals' social status impact several dimensions of social crises, including the pandemic and its consequences.

The analyses that addressed the first stage of the COVID-19 pandemic focused primarily on women's experiences such as overload by caregiving functions regarding lack of institutional care, higher risk of domestic violence resulting from increased household tensions. The above analyses also focused on hazards connected with a high rate of women's employment in healthcare, social work, commerce, and other areas that require face-to-face interactions. Another issue is sexual and reproductive health (especially the experience of pregnancy and delivery during a pandemic) (UNFPA 2020; Robertson \& Gebeloff 2020). Many of these problems occur in the context of toxic masculinity patterns and underlying androcentric socio-cultural norms.

Analyses of the above issues may conclude that certain aspects of males' social status protect them from specific social problems and make them privileged in the face of the pandemic. Simultaneously, epidemiological data indicate that more men than women die of COVID-19 worldwide (Global Health 50/50 2020, 2021; Griffith, Sharma, Holliday et al. 2020; Ewig 2020). ${ }^{4}$ According to Global Health 50/50 report based on

\footnotetext{
${ }^{4}$ Since the pandemic situation is dynamic, this paper relies on the hitherto data published until September 2020.

${ }^{5}$ Global Health 50/50 is an organization promoting gender equality in health care that designed a data tracking tool. On 25 January 2021, this data tracker had sex-disaggregated data for just $60 \%$ of the global cases and 70\% of the global deaths reported to the World Health Organization (Global Health 50/50 2021)
} 
the largest body of publicly available sex-disaggregated data from the global government sources, notwithstanding no apparent sex differences exist in the number of confirmed cases $^{6}$, more men than women have died of COVID-19 in 41 out of 47 analyzed countries taken into account in 2020 (Global Health 50/50 2020). On the global scale, the overall COVID-19 case-fatality ratio is approximately 2.4 times higher among men than among women (Global Health 50/50 2020, Griffith, Sharma, Holliday, et al. 2020). Based on data for the years 2019-2020, the proportion of men's deaths of COVID-19 amounted to 57\% in the USA (Bischof, Wolfe, Klein 2020), 70\% in Italy (Sharma, Volgman, \& Michos 2020), 75\% in China (Xie, Tong, \& Guan 2020). According to the updated Global Health 50/50 report as of 25 January 2021, at the global level, for every 10 female confirmed cases that have died, 15 male confirmed cases have died. These numbers reflect the fact that confirmed cases are evenly distributed between men (49\%) and women (51\%), but men comprise a higher proportion of hospitalizations (53\%), intensive care units admissions (68\%), and deaths (57\%) than women (Global Health 50/50 2021).

Regarding the above data, it is essential to take the gender perspective in general and men's perspective in particular while analyzing the pandemic and other public health issues. Commenting the focus on females' perspective and women's problems in sociological research concerning pandemic's consequences Christina Ewig (2020) writes: "These are crucial issues. However, what seems to be getting lost is that gender affects all of us: men, women, non-binary people, and trans people (...). The unequal death rate between men and women as a result of COVID-19 should prompt greater attention to the gendered effects of this crisis on men-particularly the role of masculinity.” The COVID-19 pandemic is shining a spotlight on neglecting men's health at local, state, national, and global levels (Griffith, Sharma, Holliday et al. 2020; Baker, White, \& Morgan 2020).

Men and women assumedly contact the virus at similar rates (Ewig 2020). The data on evenly distributed confirmed cases imply that both sexes are comparably susceptible to the disease. Since any single biological factor cannot easily explain the sex gap in COVID-19-associated with mortality, it is essential to recognize the difference between sex and gender in health outcomes and discern their mutual influences. Derek M. Griffith, Garima Sharma, Christipher Holliday et al. (2020) claim that the interaction of biological, psychological, behavioral, and social factors may put men at a disproportionate risk of death.

A study of critically ill patients carried out in China, Italy, and the USA revealed the highest mortality rate among men with comorbidities such as hypertension, cardiovascular disease, chronic kidney disease, and diabetes (Griffith, Sharma, Holliday et al. 2020; Meng, Wu, Liu et al. 2020; Richardson, Hirsch, Narasimhan et al. 2020; Reeves \& Ford 2020; Instituto Superiore di Sanita 2020). An international health research database using the TriNetX Network showed that among 14,712 male and female patients

\footnotetext{
${ }^{6}$ It should be noted that data on confirmed cases in men and women are influenced by who has access to testing in each country. "Data on testing broken down by sex is available from only a handful of countries, meaning that it is difficult to assess whether figures on confirmed cases are being skewed by certain people having greater access to testing than others." (Global Health 50/50 2020).
} 
with confirmed COVID-19, men were older and had a higher prevalence of hypertension, diabetes, coronary heart disease, obstructive pulmonary disease, and heart failure (Alkhouli, Nanjundappa, Annie et al. 2020; Griffith, Sharma, Holliday et al. 2020). The higher proportion of men suffering from comorbidities explain why men were more likely to be hospitalized than women. The above diseases are mostly derivate of life-style and culture-related, gendered patterns of responses to stress. In many societies, men are more likely to suffer from heart disease and chronic lung disease as they more frequently smoke, drink alcohol, or work in occupations that expose them to air pollution (Global Health 50/50 2020). Using nicotine and high levels of alcohol consumption can result in, or exacerbate, the underlying health conditions that make men more susceptible to the more severe course of COVID-19.

In many societies, excessive drinking and smoking are still parts of the traditional patterns of masculinity. According to WHO global data, $6.2 \%$ of all male deaths are attributable to alcohol, compared to $1.1 \%$ of female deaths. Men also have far greater rates of total burden attributed to alcohol than women $-7.4 \%$ for men compared to $1.4 \%$ for women (WHO 2011). Global Health 50/50 report reveals that men are $83 \%$ of young smokers (at the age of 15-24) and 86\% smokers at the age of 25-69 globally (in all WHO Regions) (Hawkes, Buse, \& Yoon 2018).

Using psychoactive substances such as alcohol and nicotine is a reaction to daily stress and emotional tension. Because of the males' socialization's training in hiding emotions and not dealing with them directly, smoking and drinking may be the only way of reducing the emotional tension, many men know. Using psychoactive substances as a part of toxic masculinity is an intercultural phenomenon. For example, a study carried out in 2019 on Chinese men found a greater prevalence of binge drinking when a man felt he was not living up to his society's ideal of masculinity (Ewig 2020). The stress of fulfilling gender norms may fall unevenly across socio-demographic categories such as ethnicity and class. For example, the expectation that men should be the primary breadwinner can be incredibly stressful for individuals with few economic opportunities (Ewig 2020). American studies have revealed that heavy drinking (especially among young men) has long been a part of performing traditional masculinity and, for others, the means of escaping from the stress of societal expectations for attaining masculine ideals (Ewig 2020). Independent research projects in many countries have confirmed the tendencies linking the adherence to traditional masculinity patterns with drinking and smoking. (Mullen, Watson, \& Swift 2007; Emslie, Hunt, \& Lyons 2013; Kodriati, Pursell, \& Nur Hayati 2018). Smoking (like drinking) is a stress-coping mechanism, and young men believe themselves to be physically more resilient to the harmful effects of it. As a result, they take up the habit (Ewig 2020). The older men who smoke relatively lengthy expose themselves to the unfavorable health effects of using nicotine. In this context, we can assume that the male representatives of the older age groups are at the highest risk of life-threatening COVID-19 course not only because of the sex-age combination but because of the gender-related life-style's components as well.

According to the preliminary research on people with a severe course of COVID-19, the burden of the comorbidities that put the individuals in a high-risk group may, in 
part, be driven by higher levels of risky behaviors, which are more common among men than women worldwide (Global Health 50/50 2020). Men engage in applying preventive measures to a smaller extent than women. They tend to have lower rates of hand-washing, social distancing, avoiding large public gatherings and wearing masks (Griffith, Sharma, Holliday et al. 2020; Ewig 2020). The difference between men and women in the face of pandemic addresses behavior and convictions. Men are more likely to downplay the severity of the virus's potential to harm them (Griffith, Sharma, Holliday, et al. 2020, Ewig 2020). Data from two waves of a nationally representative panel survey conducted in March and April 2020 in eight countries: Australia ( $\mathrm{n}=$ $2,010)$, Austria $(n=2,000)$, France $(n=4,036)$, Germany $(n=3,501)$, Italy $(n=1,997)$, New Zealand $(n=1,997)$, the United Kingdom $(n=2,012)$, and the United States $(n=$ 4,096 ), for a total of 21,649 respondents indicate large gender differences in the individual perception regarding the seriousness of COVID-19 as a health problem in the respondents' country (Pons, Profeta, Becher et al. 2020). The data from the first wave in all eight countries $(n=10,594)$ show that $59.0 \%$ of the female respondents considered COVID-19 to be a severe health problem, against $48.7 \%$ of the men ${ }^{7}$. In the pooled data from the second wave $(n=11,025)$, these proportions had decreased by more than 15 percentage points among both men and women, but a sizable and significant gender difference remained ${ }^{8}$. In both survey waves, the respondents evaluated how strictly they were following seven recommended rules, on a 0 to 10 scale (from "not at all" to "completely"): washing hands more often, coughing into one's elbow, ending the greeting of people by shaking hands or hugging, avoiding crowed places, keeping a physical distance from others, staying at home, and stopping visits to friends. In the second wave, additional items addressed: wearing face masks in public places, wearing gloves in public places, and leaving home less than once a day. The authors of the study have constructed an overall index of respondents' compliance with public health and social distancing rules in each wave by averaging their answers to all questions after normalizing each of them on a 0 to 1 range. According to the data, essential gender differences in compliance with rules were observed. Pooling data from all eight countries in the first wave $(n=10,602)$ indicate that compliance was markedly higher among women than among men ${ }^{9}$. Pooled data $(n=11,029)$ show that, in mid-April, general compliance had decreased (from 0.857 to 0.747 ) but remained at a high level. However, a sizable and significant gender difference persisted ${ }^{10}($ Pons, Profeta, Becher et al. 2020).

Males' beliefs and behaviors in the face of the epidemic hazard can be explained according to men's socialization patterns. The tendency to risk-taking and underestimating the risk are parts of the toxic masculinity schema that rely on the concept of “strength." This schema's key component is disguising anxiety, perceived as "weakness" (Real 1998). Many men have learned to mask their fear by anger and impulsive-aggressive behavior. Therefore, it is essential to consider how hiding fear and

\footnotetext{
${ }^{7} \mathrm{M}=0.590$ vs. 0.487 , Mdiff $=0.104,95 \%$ CI $[0.086 ; 0.121]$.

${ }^{8} \mathrm{M}=0.396$ vs. 0.330 , Mdiff $=0.067,95 \%$ CI [0.048; 0.085].

${ }^{9} \mathrm{M}=0.881$ vs. 0.832 , Mdiff $=0.049,95 \%$ CI $[0.042 ; 0.057]$

${ }^{10}(\mathrm{M}=0.776$ vs. $0.718, \mathrm{Mdiff}=0.058,95 \%$ CI $[0.051 ; 0.065])$
} 
replacing it with anger and aggression affects men's response to COVID-19 (Gupta 2020). As Jennifer Lerner, Roxana Gonzalez, Deborah Small et al. (2003) claim, fear and anger have opposing influences on people's risk perceptions, risk preferences, everyday choices, and policy support. After the terrorist attacks of 11 September 2001, the authors carried out a series of research on US national, representative sample revealing that fear heightens the subsequent perception of risk and increases the plans for precautionary measures, while anger reduces risk perception and the involvement in preventive activities (Lerner, Gonzalez, Small et al. 2003). ${ }^{11}$ The study results indicate that men tend to be more optimistic than women in the risk assessment. Males' risk estimates were lower than females' (Lerner, Gonzalez, Small et al. 2003). In the pandemic's situation, the males' reactions constructed according to traditional masculinity patterns boil down to expressing anger that reduces the perception of susceptibility and severity, which then translates into a decrease in the practice of preventive measures, such as wearing masks, hand-washing, and protests against pandemic-related restrictions (Gupta 2020). In this context, Ewig (2020) puts forward a thesis that men may tend to underrate the risk of contagion as they downplay the health consequences of smoking and drinking.

Another risk factor that should be considered addresses the occupational hazard. In many countries, men outnumber women in the low-skilled or low-paid occupations that are considered essential workers (such as food processing, transportation, delivery, warehousing, construction, manufacturing, mining). These occupations are associated with a greater risk of incidence and mortality (Robertson \& Gebeloff 2020; Griffith, Sharma, Holliday et al. 2020). An example is the mining industry since mines are the hotspots for the spread of COVID-19 infections worldwide (Leahy 2020). According to the mechanism described above, the occupational hazard may activate fear that transforms into anger. As a result, men may downplay the risk and heighten the feasibility of contagion.

A pattern that is still present in the contemporary men's behavior boils down to their resistance to seeking various forms of help, lower use of health services, including preventive health services. As a result, men are further along in their illness before they seek care. In the case of the ebola epidemic, men typically presented at a hospital on average 12 hours later in the disease than women did, which is one of the reasons, why men's death rate was higher (Global Health 50/50; Agua-Agum, Ariyarajah, Blake et al. 2016). This finding is in line with the previous research results on males' health

\footnotetext{
${ }^{11}$ The research was carried out on a nationally representative sample of Americans ( $\mathrm{N}=973$, ages 13-88). At the first stage, the survey questions included the Anxiety Subscale from the Stanford Acute Stress Reaction Questionnaire and a four-item face-valid Desire for Vengeance Scale. At the second stage, the experimental procedure was performed: the participants were randomly assigned to one of three emotional conditions (anger, sadness, or fear), then they answered questions about their mood and received two-part emotion induction: (1) the narrative task in which they had to describe what makes them angry, sad or afraid after the terrorist attacks, and (2) the audio clip about terrorism that had in pretests evoked the targeted emotions. After that, each respondent judged the risk on three levels: country, self, and the average citizen. Finally, the respondents evaluated four safety policies on a 4-point Lickert's scale anchored at 1 (strongly oppose) to 4 (strongly support) (Lerner, Gonzalez, Small et al. 2003).
} 
behavior patterns, according to which men are more likely than women to use the medical assistance only in absolute necessity - in life-threatening situations or severe pain that disturbs the normal functioning (Gillon 2007; Frąckowiak-Sochańska 2017). Consequently, they turn to specialists in a worse health condition that is more difficult to cure. This state of affairs is explained concerning the traditional schemas of masculinity, including the patterns of specifically understood strength, independence, and self-reliance. The repercussions of these masculinity patterns address somatic health and mental condition, including the suicide risk.

\section{TOXIC MASCULINITY AND SUICIDAL CRISIS IN THE CONTEXT OF PANDEMIC}

Leo Sher (2020) and Ira M. Wasserman (1992) explain the relations between pandemics and suicide by referring to Durkheimian categories of decrease in social integration and interaction during the epidemic, the pandemic's fears, and the socio-economic consequences. This thesis has been confirmed by statistical data addressing the previous epidemics such as the Spanish Flu in 1918-1919 (Wasserman 1992) and partially SARS in 2003 (Yip, Cheung, Chau, et al. 2010). Although, as Tiago Zortea, Connor Brenna, Mary Joyce et al. (2020) claim, we cannot draw a firm conclusion regarding a direct relationship between epidemics and suicide-related outcomes, evidence suggests an impact of epidemics on the circumstances in which the risk of suicidal behaviors rises (Zortea, Brenna, Joyce et al. 2020).

According to the preliminary analyses addressing the ongoing pandemic's consequences, we can put forward a thesis that the COVID-19 crisis may increase suicide rates during and after the pandemic (Sher 2020; Kawohl \& Nordt 2020; Khan, Ratele, $\&$ Arendse 2020). Considering heightened worldwide unemployment rates caused by the current pandemic, Wolfram Kawohl and Carlos Nordt (2020) estimate a global increase of between 2135 and 9570 additional suicide deaths per year. ${ }^{12}$ Leo Sher (2020) prognosticates that mental health consequences of the COVID-19 crisis, including suicidal behavior, are likely to be present for a long time and peak later than the actual pandemic. According to the research addressing the repercussions of the SARS epidemic (2002-2003), the implication of a social crisis for individuals' mental health may last much longer than the crisis itself (Lee, Wong, McAlonan et al. 2007; Mak, Chu, Pan et al. 2009; Lai, Ma, Wang et al. 2020; Maunder, Hunter, Vincent et al. 2003; Bai,

\footnotetext{
${ }^{12}$ The authors prepared a model that allowed to examine the effect of unemployment on suicide based on global public data from 63 countries, and they observed that suicide risk was elevated by $20-30 \%$ when associated with unemployment during 2000-2011 (including the economic crisis in 2008). This model was applied to predict the effects of the currently expected rise in the unemployment rate resulting from the COVID-19 pandemic on suicide rates. The authors applied the overall estimates to World Bank Open Data (worldwide number in the labor force in 2019, the unemployment rate for 2019, and male and female populations in 2018 in the four age groups). The expected number of job losses due to COVID-19 were taken from the International Labor Organization's press release from 18 March 2020, reporting a decline of 24.7 million jobs as a high scenario and 5.3 million jobs lost as a low scenario. In the high scenario, the worldwide unemployment rate would increase from $4.936 \%$ to $5.644 \%$, associated with the increased number of suicides of about 9570 per year. In the low scenario, the unemployment would increase to $5.088 \%$, associated with an increase of about 2135 suicides (Kawohl \& Nordt 2020).
} 
Lin, Chue et al. 2004; Chua, Cheung, Cheung 2004). According to Antoinette M Lee, Josephine G W S Wong, Grainne M McAlonan, et al. (2007) ${ }^{13}$, SARS survivors had higher stress levels during the outbreak, compared with control subjects ${ }^{14}$, and this persisted 1 year later ${ }^{15}$ without signs of decrease. In 2004, SARS survivors also showed worrying levels of depression, anxiety, and posttraumatic symptoms (Lee, Wong, McAlonan et al. 2007). In this context, the suicide rates and socio-demographic characteristics of persons who undertake suicidal behaviors during and after the Covid-19 pandemic require dedicated attention (Reger, Stanley, \& Joiner 2020).

The state of the pandemic and its social, economic, and political consequences (likewise all social crises) burden the individuals with the immense stress that impacts their mental condition (Dong \& Bouey 2020; Frąckowiak-Sochańska 2020). WHO study on the results of the world economic crisis in 2008 on the individuals' mental health revealed the increase of suicide rates, addictions and deaths due to alcohol abuse, and the incidence of depression (WHO 2011). ${ }^{16}$ The two first issues addressed men primarily. As to depression's prevalence, the number of men who have this mental disease may be underrated, since the official psychiatric classifications of symptoms ICD (International Classification of Diseases) and DSM (Diagnostic Statistical Manual) include symptoms that are traditionally associated with femininity, such as openly manifested sadness, tearfulness, withdrawal from activities, and lack of feeling pleasure. Therefore, some experts, directly or indirectly, postulate broadening the official classification by introducing the untypical depressive symptoms that are more common among men (Chodkiewicz \& Miniszewska 2016; Cochran Rabinowitz 2003).

Recent research reports indicate that various socio-economic, psychological, and health-related impacts of the Covid-19 pandemic may heighten the risk of suicidal behaviors (Khan, Ratele, \& Arendse 2020; Reger, Stanley, \& Joiner 2020; Gunnell, Appleby, Arensman et al. 2020). Uncertainties caused by the Covid-19 pandemic, along with global responses such as lockdowns, have heightened depression, anxiety, isolation, loneliness, financial concerns, the risk of job loss, anger, irritability, relationship conflicts, post-traumatic stress disorder, fears, and increased use of alcohol and nicotine

\footnotetext{
${ }^{13}$ The authors used the 10-item Perceived Stress Scale (PSS-10) to assess SARS survivors treated in 2 major hospitals (non-healthcare workers, $n=49$; healthcare workers, $n=30$ ) in 2003. They invited SARS survivors from the same hospitals (non-healthcare workers, $n=63$; healthcare workers, $n=33$ ) to complete the PSS-10 again in 2004. At that time, they were also asked to complete the General Health Questionnaire (GHQ-12) and measures of depression, anxiety, and posttraumatic symptoms. PSS-10 scores were also obtained from matched community control subjects during the outbreak $(n=145)$ and again in $2004(\mathrm{n}=112)$ (Lee, Wong, \& McAlonan 2007).

${ }^{14}(\mathrm{PSS}-10$ scores $=19.8$ and 17.9 , respectively; $\mathrm{P}<0.01)$

${ }^{15}(\mathrm{PSS}-10$ scores $=19.9$ and 17.3 , respectively; $\mathrm{P}<0.01)$

${ }^{16}$ Shu-Sen Chang, David Stuckler, Paul Yip et al. (2013) investigated the 2008 global economic crisis's impact on international trends in suicide. Based on data from 54 countries (included in WHO and USA databases) addressing people aged 15 or above, the authors found that the increases in suicide mainly occurred in men in the 27 European and 18 American countries. The suicide rates were $4.2 \%$ (3.4\% to $5.1 \%$ ) and $6.4 \%$ (5.4\% to $7.5 \%$ ) higher, respectively, in 2009 than expected if the earlier trends had continued. There was no change in European countries for women, and the increase in the Americas was smaller than in men (2.3\%) (Shu-Sen Chang, David Stuckler, Paul Yip et al. 2013).
} 
(Zortea, Brenna, \& Joyce 2020; Frąckowiak-Sochańska 2020). These factors intensify the risk of suicidal behaviors in people traditionally considered vulnerable and those who did not belong to the risk groups before the pandemic (Suicide Awareness Voices of Education 2020; Courtet, Olié, Debien et al. 2020).

According to the world's epidemiological data, men demonstrate higher suicide rates than women at all times and across regions, and ethnic and socioeconomic groups (Vijayakumar 2015; Naghavi 2019; Cleary 2019), and current sources indicate similar trends during the Covid-19 pandemic (Mooney, Kaplan, \& Denis 2020). As reported by WHO, men worldwide commit suicide on average twice as often as women (WHO 2019). The most significant difference was found in Europe, where the rates of suicidal deaths amounted to 6,6 women and 24,7 men per 100000 population, and in the Americas, analogical numbers reached 4,6 for women and 15,1 for men. ${ }^{17}$

Gender differences address not only the prevalence of suicidal behavior but the correlations with socio-economic variables as well. Only in men's case has there been a negative correlation between income per capita and suicidal behavior (Sher 2006; Chodkiewicz \& Miniszewska 2016). Across the socio-psychological literature, there is a plethora of evidence that associates male suicidal behaviors with triggers such as joblessness, unemployment, failure at work, relationship strains, depression, hopelessness, and substance abuse disorders. In women, the most important triggers are personal problems and complications within interpersonal relationships (Coleman, Kaplan, \& Casey 2011; Yang, Lau, Wanget al. 2019; Chodkiewicz \& Miniszewska 2016). Men significantly more often than women commit suicide under the influence of alcohol and drugs. The relation between substance abuse and suicidal behaviors is more robust in men than in women (Payne, Swami, \& Stanistreet 2008; Chodkiewicz \& Miniszewska 2016). Early reports about male suicide during the COVID-19 pandemic agree about several triggering factors: financial insecurities, fear of infections, social stigma, anxiety, and excessive regulations (Thakur \& Jain 2020).

Suicide is strongly related to depression, which prevalence among men is often underrated due to socio-cultural schemas. In this context, it is essential to understand the mechanisms of male depression that are often interfered with by other health problems such as impulsive and risky behavior and substance abuse. This comprehensive knowledge is crucial from the perspective of suicide prevention. Depressive and anxiety disorders are the derivate of stress since chronic stress transforms into anxiety and chronic anxiety converts into depression (Murawiec \& Wierzbiński 2016). Whereas stress affects people regardless of gender, the individuals' reactions to stress reflect the gender schemas. Women are usually more likely than men to manifest openly their anxiety and depression. They search for social support and professional help, whereas men are more likely to hide their anxiety and depression behind impulsiveness, aggression, alcohol and drug abuse, and medicine misuse (Khan, Ratele, \& Arendse 2020; Chodkiewicz \& Miniszewska 2016).

The clinical picture of male depression contains aggressiveness, anger explosions,

\footnotetext{
${ }^{17}$ In Africa, women's suicide rate was 4,8 and, and men's 9,9 per 100000 population; in Eastern Mediterranean accordingly: 2,7 and 5,1, in South-East Asia, 11,6 and 14,8 and Western Pacific, 9,4 and 10,9 (WHO 2019).
} 
substance abuse (alcohol, drugs, nicotine), risky behaviors such as excessive engagement in work, physical activities, hazardous driving, and unsafe sexual contacts (Magovcevic \& Addis 2008; Sher 2006; Chodkiewicz \& Miniszewska 2016). ${ }^{18}$ Among the dominant symptoms may appear: the significant decline of stress resilience, burnout, subjective feeling of constant pressure and tension, withdrawal from family and friends relations, and lack of control that has not appeared before (or occurred to a notably smaller extent). On the contrary, men, less frequently than women, manifest sadness, feeling of guilt, helplessness, and hopelessness. Depressive men may more strongly suppress the hurtful emotions and suffer from undefined somatic ailments (Magovcevic \& Addis 2008; Sher 2006; Cohran \& Rabinowitz 2003; Rice, Fallon, Aucote et al. 2013; Chodkiewicz \& Miniszewska 2016). ${ }^{19}$

According to James Mahalik, Benjamin Locke, Larry Ludlow, et al. (2003), the results in a test measuring the risk of developing male depression (Male Depression Risk Scale) correlated positively with the conformism to traditional gender norms measured by the Conformity to Masculine Norms Inventory (Chodkiewicz \& Miniszewska 2016). The most vital relations have been noted between the attachment to the traditional masculinity norms and risky behaviors and manifestations of anger and aggression (Rice, Fallon, Aucote et al. 2013; Chodkiewicz \& Miniszewska 2016). ${ }^{20}$ The relations between adherence to traditional masculinity and atypical symptoms of depression include many mechanisms. For example, suppose a man considers the classic symptoms of depression, such as sadness and tearfulness, as "not male" display of weakness, he can hide them from other people and damp by using psychoactive substances (Magovcevic \& Addis 2008; Möller-Leimkühler \& Yücel 2010; Chodkiewicz \& Miniszewska 2016). Another mechanism concerns the inability to self-detection of depressive symptoms. Some research findings indicate that men who strictly follow the norm of emotional self-control have significant difficulties recognizing their low mood and conscious feeling of regret and sadness (Levant, Richmond, Majors et al. 2003; Chodkiewicz \& Miniszewska 2016). Moreover, the persons who share the belief

\footnotetext{
${ }^{18}$ The most common research tools to study male depression are the Gotland Male Depression Scale (Zierau, Bille, Rutz et al. 2002), the Male Depression Risk Scale (Rice, Fallon, Aucote et al. 2013), and the Masculine Depression Scale (Magovcevic \& Addis 2008).

${ }^{19}$ However, the above symptoms do not occur in all depressive men, among whom some suffer from the typical depressive manifestations, and some - experience typical and untypical symptoms (Martin, Neighbors, \& Griffith 2013; Chodkiewicz \& Miniszewska 2016). Moreover, because of gender roles' transformation, the untypical symptoms of depression may be observed in women. Some findings indicate the lack of differences between men and women in the prevalence of depressive symptoms considered as typically male (Möller-Leimkühler \& Yücel 2010; Martin, Neighbors, \& Griffith 2013; Chodkiewicz \& Miniszewska 2016). In this context, Mariola Magovcevic and Michael Addis (2008) submit the concept of "male depression" to criticism and claim that it relies on the dichotomy "male-female depression" without considering possible intermediate states (Chodkiewicz \& Miniszewska 2016). According to this line of thought, the classification of depressive symptoms should include both typical and untypical manifestations in people of all genders.

${ }^{20}$ Concomitantly, no similar correlation was found concerning the Beck Depression Inventory, which measures the classic symptoms of depression (Rice, Fallon, Aucote et al. 2013; Chodkiewicz \& Miniszewska 2016).
} 
that "one should deal with problems on one's own," much later (if ever), ask other people for help. That can notably worsen the personal, family, or financial situation of an individual in depression, extent the therapy's duration, and heighten the risk of suicide (Addis 2008; Chodkiewicz \& Miniszewska 2016; Frąckowiak-Sochańska 2017).

Anne Cleary (2012) carried out individual in-depth interviews with 52 young men after serious suicide attempts. The interviewees noted that before having decided to end their lives, they experienced a very high level of emotional pain and suffering, which they did not reveal to people around. They also were not able to identify their symptoms accurately, and they did not seek help. They tried to deal with the mental pain by using alcohol or drugs, which made their condition even worse and finally led to a feeling that death is the only solution. ${ }^{21}$

\section{CONCLUSIONS AND RECOMMENDATIONS}

The above analyses conclude that similar factors may lead to higher men's mortality because of COVID-19 and suicidal death resulting from life crises caused by the pandemic. Therefore, the male patterns of responses to stress, including behaviors aiming to free themselves from tension, should be subjected to the reflection because of their nonadaptability to social trauma caused by the global pandemic crisis.

Pandemic brings a plethora of challenges, one of which is health education addressed to men. The educational campaigns should take into consideration the diversity of men as a social category. Individuals who define themselves as men belong to many social categories, depending on socio-demographic variables such as age, social class, religion, race, ethnicity, nationality, place of residence, (dis)ability, sexuality, family status. These categories overlap, interweave, and influence one another. They also influence the significant behaviors, patterns of emotional reactions, and cognitive habits considered when health issues are discussed. As the health problems are a derivate of toxic masculinity norms, one of the most critical challenges boils down to a question, how to communicate the need of changing these norms to the men who strongly identify themselves with this version of masculinity. While discussing the mental health promotion and therapy addressed to men, Mark S. Kiselica and Matt Englas-Carlson (2012) suggest referring to some traditional masculinity values. An example of these values is task orientation that can be a source of motivation for healthy behavior. Independence can be a resource that allows being critical about the dysfunctional stereotypes of masculinity. Courage, though, may allow introducing the changes in men's life. Moreover, the motivation for withdrawal from dysfunctional masculinity patterns could rely on the values connected with the males' social roles of partner, father, and breadwinner (Kiselica \& Englar-Carlson 2012). These suggestions may help promote preventive means in the COVID-19 pandemic and suicide prevention programs focused on men.

\footnotetext{
${ }^{21}$ These findings are commensurate with the research "Epidemiology of mental disorders and access to mental health care" in Poland in 2012. According to this research, men, more often than women, declared that they could not count for other people's support (particular help or a talk) while struggling with problems. (Moskalewicz, Kiejna, \& Wojtyniak 2012).
} 
FUNDING: This research received no external funding.

CONFLICT OF INTEREST: The author declares no conflict of interest.

\section{REFERENCES}

Addis, Michael E. 2008. "Gender and depression in men." Clinical Psychology Science and Practice 15(3): 153-168. https://doi.org/10.1111/j.1468-2850.2008.00125.x

Agua-Agum, Junerlyn, Archchun Ariyarajah, Isobel M. Blake et al. 2016. "Ebola Virus Disease among Male and Female Persons in West Africa.” The New England Journal of Medicine 374:96-98, DOI: 10.1056/NEJMc1510305.

Alexander, Jeffrey. 2004. “Toward a Theory of Cultural Trauma.” in Cultural Trauma and Collective Identity, edited by J. C. Alexander, R. Eyerman, B. Giesen et al. Berkeley: University of California Press.

Alkhouli, Mohamad, Aravinda Nanjundappa, Frank Annie et al. 2020. "Sex differences in COVID-19 case fatality rate: insights from a multinational registry.” Mayo Clinic Proceedings 95(8): 1613-1620. DOI: 10.1016/i.mayocp.2020.05.014

Anderson, Eric. 2009. Inclusive masculinity: The changing nature of masculinities 1 th ed. New York: Routledge.

Bai, Ya Mei, Chao-Cheng Lin, Ching-Mo Chue et al. 2004. "Survey of stress reactions among health care workers with the SARS outbreak." Psychiatric Services 55(9): 1055-1057. doi:10.1176/appi.ps.55.9.1055.

Baker, Peter, Alan White, \& Rosemary Morgan. 2020. “Men's health: COVID-19 pandemic highlights need for overdue policy action.” Lancet 2395(1024)1: 18861888. DOI: https://doi.org/10.1016/S0140-6736(20)31303-9

Bischof, Evelyne, Jeannette Wolfe, \& Sabra Klein. 2020. "Clinical trials for COVID-19 should include sex as a variable.” The Journal of Clinical Investigation 130(7): 3350-3352. https://doi.org/10.1172//CI139306.

Bridges, Tristan \& Cheri J. Pascoe. 2014. "Hybrid Masculinities: New Directions in the Sociology of Men and Masculinities.” Sociology Compass 8(3): 246-258. https:// doi.org/10.1111/soc4.12134

de Boise, Sam. 2019. "Editorial: is masculinity toxic?" Norma, International Journal for Masculinity Studies 14(3): 147-151. https://doi.org/10.1080/18902138.2019.1654 $\underline{742}$.

Chang, Shu-Sen, David Stuckler, Paul Yip, \& David Gunnell. 2013. “Impact of 2008 global economic crisis on suicide: time trend study in 54 countries.” BMJ 347: f5239. doi: 10.1136/bmj.f5239

Chodkiewicz, Jan \& Joanna Miniszewska. 2016. “Męska depresja - koncepcja, metody pomiaru i związki z zachowaniami samobójczymi (Male depression - the concept, measurement tools and relationships with suicidal behaviours)." Psychiatria i Psychologia Kliniczna 16(1): 33-37. DOI: 10.15557/PiPK.2016.0006.

Chua, Siew E., Vinci Cheung, Charlton Cheung et al. 2004. "Psychological effects of the SARS outbreak in Hong Kong on high-risk health care workers.” Canadian Journal 
of Psychiatry 49(6): 391-393. DOI:10.1177/070674370404900609

Cleary, Anne. 2012. "Suicidal action, emotional expression, and the performance of masculinities." Social Science \& Medicine 74(4): 498-505. DOI: 10.1016/j. socscimed.2011.08.002

Cleary, Anne. 2019. The gendered landscape of suicide: Masculinities, emotions, and culture. Cham: Palgrave Macmillan.

Cochran, Sam V. \& Frederic E. Rabinowitz. 2003. "Gender-sensitive recommendations for assessment and treatment of depression in men." Professional Psychology: Research and Practice 34(2): 132-140. https://doi.org/10.1037/0735-7028.34.2.132

Coleman, Daniel, Mark S. Kaplan, \& John T. Casey. 2011. "The social nature of male suicide: A new analytic model.” International Journal of Men's Health 10(3): 240252. https://doi.org/10.3149/jmh.1003.240

Connel, Reawyn \& James Messerschmidt. 2020. "Hegemonic Masculinity. Rethinking the Concept.” Gender \& Society 19(6): 829-859. https://doi. org/10.1177/0891243205278639

Courtet, Philippe, Emile Olié, \& Christophe Debien. 2020. "Keep socially (but not physically) connected and carry on: Preventing suicide in the age of COVID-19." Journal of Clinical Psychiatry 81(3). https://doi.org/10.4088/JCP.20com13370

Dong, Lu \& Jennifer Bouey. 2020. "Public Mental Health Crisis during COVID-19 Pandemic, China.” Emerging Infectious Diseases 26(7): 1616-1618. DOI:10.3201/ eid2607.200407

Elliott, Karla. 2016. “Caring masculinities: theorizing an emerging concept.” Men and Masculinities 19(3): 240-259. DOI: 10.1177/1097184X15576203

Emslie, Carol, Kate Hunt, \& Antonia Lyons. 2013. "The role of alcohol in forging and maintaining friendships amongst Scottish men in midlife.” Health Psychology 32(1): 33-41. https://doi.org/10.1037/a0029874

Ewig, Christina. 2020. "Gender, masculinity, and COVID-19. The Gender Policy Report". Retrieved September 1, 2020 (https://genderpolicyreport.umn.edu/gender-masculinity-and-covid-19/).

Ford, Tiffany N. \& Robert V. Reeves. 2020. "COVID-19 much more fatal for men, especially taking age into account.” Retrieved September 18, 2020 (https:// spp.umd.edu/research-impact/publications/covid-19-much-more-fatal-formen-especially-taking-age-into-account).Frąckowiak-Sochańska, Monika. 2017. „Mężczyźni w procesie psychoterapii a normatywne schematy męskości-ciągłość i zmiana.” Miscellanea Anthropologica et Sociologica 18(2): 91-114. https://czasopisma.bg.ug.edu.pl/index.php/maes/issue/view/257/131

Frąckowiak-Sochańska, Monika. 2020. "Mental health in the pandemic times." Society Register 4(3): 67-78. https://doi.org/10.14746/sr.2020.4.3.03

Gillon, Ewan. 2007. “Gender differences in help-seeking.” Therapy Today 18(10): 1316.

Global Health 50/50. 2020. “COVID-19 sex-disaggregated data tracker.” Retrieved September 1, 2020 (https://globalhealth5050.org/covid19/sexdisaggregated- data-tracker).

Global Health 50/50. 2021. "The COVID-19 sex-disaggregated data tracker. Janu- 
ary update report." Retrieved February 19, 2021 (https://globalhealth5050.org/ wp-content/uploads/January-2021-the-covid-19-sex-disaggregated-data-tracker-update.pdf).

Griffith, Derek M., Garima Sharma, Christopher S. Holliday et al. 2020. "Men and COVID-19: A Biopsychosocial Approach to Understanding Sex Differences in Mortality and Recommendations for Practice and Policy Interventions." Preventing Chronic Disease. Public Health Research, Practice and Policy 17(E63): 200247. DOI: http://dx.doi.org/10.5888/pcd17.200247

Gunnell, David, Louis Appleby, Ella Arensman et al. 2020. "Suicide risk and prevention during the COVID-19 pandemic.” The Lancet Psychiatry 7(6): 468-471. https:// doi.org/10.1016/S2215-0366(20)30171-1

Gupta, Sujata. 2020. "How fear and anger change our perception of coronavirus risk." Science News: Health \& Medicine. Retrieved September 19, 2020 (https://www. sciencenews.org/article/coronavirus-covid-19-how-fear-anger-change-riskperception).

https://en.wikipedia.org/wiki/COVID-19_pandemic, Retrieved September 11, 2020.

Harsin, Jayson. 2020. "Toxic White masculinity, post-truth politics and the COVID-19 infodemic.” European Journal of Cultural Studies 23(6): 1060-1068. https://doi. org/10.1177/1367549420944934.

Hawkes, Sarah, Kent Buse, \& Soon-Young Yoon. 2018. “Gender-Responsive Tobacco Control: Evidence and Options for Policies and Programmes Report Summary." Retrieved February 19, 2021 (https://globalhealth5050.org/wp-content/uploads/2018/09/Report-Summary-Gender-and-Tobacco.pdf).

Instituto Superiore di Sanita. 2020. "Characteristics of COVID-19 Patients Dying in Italy.” Retrieved February 19, 2021 (https://www.epicentro.iss.it/en/coronavirus/ bollettino/Report-COVID-2019_27_january_2021.pdf).

Jewkes, Rachel, Robert Morrell, \& Jeff Hearn. 2015. "Hegemonic masculinity: combining theory and practice in gender interventions.” Culture, Health \& Sexuality 17(S2): S112-S127. http://dx.doi.org/10.1080/13691058.2015.1085094

Kawohl, Wolfram \& Carlos Nordt. 2020. "COVID-19, unemployment, and suicide." The Lancet Psychiatry 7(5): 389-390. https://doi.org/10.1016/S2215-0366(20)30141-3

Khan, Anisur R., Kopano Ratele, \& Najuwa Arendse. 2020. "Men, Suicide, and Covid-19: Critical Masculinity Analyses and Interventions.” Postdigital Science and Education. https://doi.org/10.1007/s42438-020-00152-1

Kimmel, Michael S. 1994. "Foreword.” in Theorizing Masculinities, edited by H. Brod, M. Kaufman. Thousand Oaks, London, New Dehli: SAGE Publications.

Kiselica, Mark S., Matt Englar-Carlson. 2012. "Identifying, affirming, and building upon male strengths: the positive psychology/positive masculinity model of psychotherapy with boys and men." Psychotherapy, Theory, Research, Practice, Training 3(47): 276-287. DOI: $10.1037 / \mathrm{a} 0021159$

Kodriati, Nurul, Lisa Pursell, \& Elli Nur Hayati. 2018. "A scoping review of men, masculinities, and smoking behavior: The importance of settings." Global Health Action 11(3): 37-48. https://doi.org/10.1080/16549716.2019.1589763 
Lai, Jianbo, Simeng Ma, Ying Wang et al. 2019. "Factors Associated With Mental Health Outcomes Among Health Care Workers Exposed to Coronavirus Disease 2019." JAMA Network Open 3(3): e203976. DOI: 10.1001/jamanetworkopen.2020.3976

Leahy, Stephen. 2020. "Mines are hotspots for the spread of Covid-19, study finds." The Guardian, 5 June. Retrieved September 10, 2020 (https://www.theguardian. com/environment/2020/jun/05/mines-coronavirus-hotspots-report-us-canada).

Lee, Antoinette M., Josephine GWS Wong, Grainne M. McAlonan et al. 2007. "Stress and psychological distress among SARS survivors one year after the outbreak.” The Canadian Journal of Psychiatry 52(4): 233-240. DOI:10.1177/070674370705200405

Lerner, Jennifer S., Roxana M. Gonzalez, Deborah Small et al. 2003. "Effects of fear and anger on perceived risks of terrorism: a national field experiment.” Psychological Science 14(2): 144-150. https://doi.org/10.1111/1467-9280.01433

Levant, Ronald F., Katherine Richmond, Richard Majors et al. 2003. "A multicultural investigation of masculinity ideology and alexithymia." Psychology of Men and Masculinity 4(2): 91-99.

Magovcevic, Mariola \& Michael E. Addis. 2008. “The Masculine Depression Scale: Development and psychometric evaluation.” Psychology of Men \& Masculinity, 9(3): 117-132. https://doi.org/10.1037/1524-9220.9.3.117

Mahalik, James R., Benjamin D. Locke, Larry H. Ludlow et al. 2003. “Development of the conformity to masculine norms inventory." Psychology of Men \& Masculinity 4(1): 3-25. DOI: 10.1037/1524-9220.4.1.3

Mak, Ivan Wing Chit, Chung Ming Chu, \& Pey Chyou Pan. 2009. "Long-term psychiatric morbidities among SARS survivors.” General Hospital Psychiatry 31(4): 318326. DOI:10.1016/j.genhosppsych.2009.03.001

Martin, Lisa A, Harold W. Neighbors, \& Derek M. Griffith. 2013. “The experience of symptoms of depression in men vs. women: analysis of the National Comorbidity Survey Replication.” JAMA Psychiatry 70(10): 1100-1106. DOI:10.1001/jamapsychiatry.2013.1985

Maunder, Robert, Jonathan Hunter, Leslie Vincent et al. 2003. “The immediate psychological and occupational impact of the 2003 SARS outbreak in a teaching hospital.” CMAJ 168(10): 1245-1251. Retrieved March 31, 2020 (https://www.ncbi. nlm. nih.gov/pmc/articles/PMC154178/).

Meng, Yifan, Wu Ping, Lu Wanrong et al. 2020. “Sex-specific clinical characteristics and prognosis of coronavirus disease-19 infection in Wuhan, China: a retrospective study of 168 severe patients.” PLOS Pathogens 16(4): e1008520. https://doi. org/10.1371/journal.ppat.1008520

Merton, Robert. 1968. Social theory and social structure. New York: The Free Press.

Möller-Leimkühler, Anne Maria, \& Mete Yücel. 2010. "Male depression in females?" Journal of Affective Disorders 121(1-2): 22-29. https://doi.org/10.1016/j. jad.2009.05.007

Mooney, Chris, Sarah Kaplan, \& Brady Denis. 2020. "All across the United States, the coronavirus is killing more men than women, data show." The Washington Post, 5 April. Retrieved September 20, 2020 (https://www.washingtonpost.com/ health/2020/04/04/coronavirus-men/). 
Moskalewicz, Jacek, Andrzej Kiejna, \& Bogdan Wojtyniak. 2012. Kondycja psychiczna mieszkańców Polski. Raport z badań Epidemiologia zaburzeń psychiatrycznych i dostęp do psychiatrycznej opieki zdrowotnej - EZOP Polska. Warszawa: Instytut Psychiatrii i Neurologii.

Muennich Cowell, Julia, 2012. "Literature Reviews as a Research Strategy." The Journal of School Nursing 28(5): 326-327. https://doi.org/10.1177/1059840512458666

Mullen, Kenneth, Jonathan Watson, Jan Swift et al. 2007. "Young men, masculinity, and alcohol." Drugs: education, prevention, and policy 14(2): 151-165. DOI: $10.1080 / 09687630600997816$

Murawiec, Sławomir \& Piotr Wierzbiński. 2016. Depresja 2016. Gdańsk: Via Medica.

Naghavi, Mohsen. 2019. "Global, regional, and national burden of suicide mortality 1990 to 2016: Systematic analysis for the global burden of disease study.” British Medical Journal 364: 194. https://doi.org/10.1136/bmj.194

Pappas, Stephanie. 2019. "APA issues first-ever guidelines for practice with men and boys." Monitor on Psychology 50(1): 34-39. Retrieved February 22, 2021 (https:// www.apa.org/education/ce/guidelines-practice-men-boys.pdf).

Payne, Sarah, Viren Swami, \& Debbi L. Stanistreet. 2008. “The social construction of gender and its influence on suicide: a review of the literature." Journal of Men's Health 5(1): 23-35. DOI: 10.1016/j.jomh.2007.11.002

Pini, Barbara, \& Bob Pease. 2013. Men, Masculinities and Methodologies. London: Palgrave Macmillan.

Pons, Vincent, Paola Profeta, Michael Becher, Sylvain Brouard, \& Martial Foucault. 2020. "Gender differences in COVID-19 attitudes and behavior: Panel evidence from eight countries." PNAS 117(44): 27285-27291. https://doi.org/10.1073/ pnas.2012520117.

Real, Terrence. 1998. I Don't Want to Talk about It: Overcoming the Secret Legacy of Male Depression. Hemel Hempstead: Prentice-Hall.

Reger, Mark. A., Ian. H. Stanley, \& Thomas E. Joiner. 2020. "Suicide mortality and coronavirus disease 2019-a perfect storm?.” JAMA Psychiatry. Published online 10 April 2020. https://doi.org/10.1001/jamapsychiatry.2020.1060

Rice, Simon M., Barry J. Fallon, Helen M. Aucote et al. 2013. “Development and preliminary validation of the Male Depression Risk Scale: furthering the assessment of depression in men." Journal of Affective Disorders 151(3): 950-958. DOI: 10.1016/j. jad.2013.08.013

Richardson, Safiya, Jamie S. Hirsch, \& Mangala Narasimhan et al. 2020. "Presenting characteristics, comorbidities, and outcomes among 5700 patients hospitalized with COVID-19 in the New York City area." JAMA 323(20): 2052-2059. DOI:10.1001/jama.2020.6775

Robertson, Campbell, Robert Gebeloff. 2020. "How millions of women became the most essential workers in America." New York Times. 18 April. Retrieved September 18, 2020 (https://www.nytimes.com/2020/04/18/us/coronavirus-women-essential-workers.html).

Sama, Iziah E., Alice Ravera, Bernadet T. Santema et al. 2020. "Circulating plasma concentrations of angiotensin-converting enzyme 2 in men and women with heart 
failure and effects of renin-angiotensin-aldosterone inhibitors.” European Heart Journal 41(19): 1810-1817. DOI: 10.1093/eurheartj/ehaa373

Sharma, Garima, Annabelle Santos Volgman, \& Erin Michos. 2020. “Sex differences in mortality from COVID-19 pandemic: are men vulnerable and women protected? Global health report.” JACC Case Report 2(9): 1407-1410. doi: 10.1016/i.jaccas.2020.04.027

Sher, Leo. 2006. "Per capita income is related to suicide rates in men but not in women." The Journal of Men's Health \& Gender 3(1): 39-42. DOI: 10.1016/j. jmhg.2005.04.016

Sher, Leo. 2020. “The impact of the COVID-19 pandemic on suicide rates.” QJM: An International Journal of Medicine 1-6. DOI: 10.1093/qjmed/hcaa202

Smith, James, Derek M. Griffith, Alan White, Peter Baker, Daphne C. Watkins. Murray Drummond, \& Andrea Semlow. 2020. “COVID-19. Equity and Men's Health: Using Evidence to Inform Future Public Health Policy, Practice and Research Responses to Pandemics.” International Journal of Men's Social and Community Health 3(1): e48-e64. DOI: 10.22374/ijmsch.v3i1.42

Solnit, Rebecca. 2020. “Masculinity as radical selfishness.” Literary Hub. 29 May. Retrieved February 22, 2021. (https://ithub.com/masculinity-as-radical-selfishness-rebecca-solnit-on-the-maskless-men-of-the-pandemic/).

Suicide Awareness Voices of Education. 2020. "Preventing suicide during and after the Covid-19 pandemic”. Retrieved September 20, 2020 (https://save.org/wp-content/uploads/2020/03/COVID-19-Tips-Final.pdf).

Sztompka, Piotr. 2002. Socjologia. Analiza społeczeństwa. Cracow: Znak Publishing.

Thakur, Vikram \& Anu Jain, A. 2020. “COVID 2019-suicides: a global psychological pandemic." Brain, Behavior, and Immunity 88: 952-953. https://doi.org/10.1016/j. bbi.2020.04.062

Thakur, Vikram \& Anu Jain. 2020. “COVID 2019-suicides: a global psychological pandemic.” Brain, Behavior and Immunity 88: 952-952. https://doi.org/10.1016/j. bbi.2020.04.062

UNFPA. 2020. “COVID-19: A Gender Lens. Protecting sexual and reproductive health and rights and promoting gender equality." United Nations Population Fund. Retrieved August 29, 2020 (https://www.unfpa.org/resources/covid-19-genderlens).

Vijayakumar, Lakshmi. 2015. “Suicide in women.” Indian Journal of Psychiatry 57(2): S233-S238. https://doi.org/10.4103/0019-5545.161484

Wasserman, Ira, M. 1992. "The impact of epidemic, war, prohibition and media on suicide: the United States, 1910-1920." Suicide and Life-Threatening Behavior 22(2): 240-254. https://doi.org/10.1111/j.1943-278X.1992.tb00231.x

Whittemore, Robin \& Kathleen Knafl. 2005. "The integrative review: Updated methodology.” Journal of Advanced Nursing 52(5): 546- 553. https://doi.org/10.1111/ j.1365-2648.2005.03621.x

World Health Organization Regional Office for Europe. 2011. Impact of economic crisis on mental health. Geneva: WHO.

WHO. 2011. Global status report on alcohol and health. Geneva. Retrieved February 19, 
2021 (https://www.who.int/substance_abuse/publications/global_alcohol_report/msbgsruprofiles.pdf).

World Health Organization. 2019. Suicide in the world. Global Health Estimates. Retrieved September 20, 2020 (apps.who.int/iris/bitstream/handle/10665/326948/ WHO-MSD-MER-19.3-eng.pdf).

Xie, Jianfeng, Zhaohui Tong, Xiangdong Guan, Bin Du, \& Haibo Qiu. 2020. "Clinical characteristics of patients who died of coronavirus disease 2019 in China." JAMA Netw Open 3(4): e205619. doi:10.1001/jamanetworkopen.2020.5619

Yang, Xue, Joseph T.F. Lau, Zixin Wanget et al. 2019. "Prevalence of binge drinking and relationships between masculine role discrepancy and binge drinking via discrepancy stress among Chinese men.” Drug and Alcohol Dependence 196: 57-61. https://doi.org/10.1016/j.drugalcdep.2018.12.013

Yip, Paul S, Yee T.D. Cheung, Pui H. Chau et al. 2010. "The impact of epidemic outbreak: the case of severe acute respiratory syndrome (SARS) and suicide among older adults in Hong Kong." Crisis 31(2): 86-92. DOI: 10.1027/0227-5910/a000015 Zierau Finn, Anne Bille, Wolfgang Rutz et al. 2002. "The Gotland Male Depression Scale: A validity study in patients with alcohol use disorder." Nordic Journal of Psychiatry 56(4): 265-271. https://doi.org/10.1080/08039480260242750

Zortea, Tiago, Connor Brenna, Mary Joyce et al. 2020. “The impact of infectious disease-related public health emergencies on suicide, suicidal behaviour, and suicidal thoughts: a systematic review." Retrieved September 15, 2020 (https:// covid19mentalhealthresearch.ca/wp-content/uploads/2020/06/HATCHER-Initial-Knowledge-Synthesis-2020-06-22.pdf).

\section{BIOGRAPHICAL NOTE}

Monika Frąckowiak-Sochańska, Ph.D., is an assistant professor at the Faculty of Sociology, Adam Mickiewicz University in Poznań, Poland. She is interested in the sociology of mental health, gender studies, sociology of values, and sociology of helping professions.

OPEN ACCESS: This article is distributed under the terms of the Creative Commons Attribution Non-commercial License (CC BY-NC 4.0) which permits any non-commercial use, and reproduction in any medium, provided the original author(s) and source are credited.

ARTICLE HISTORY: Received 2020-09-21 / Accepted 2021-02-25 
